\title{
Study on the Four-channel Skin-hearing Aid Based on Morse Codes
}

\author{
Jianwen Li \& Yuanyuan Hou \\ College of Electrical \& Information Engineering \\ Shaanxi University of Science \& Technology \\ Xi'an 710021, China \\ Jianghong Li \\ College of Power and Energy \\ Northwestern Polytechnical University \\ Xi' an 710021, China \\ E-mail: tangwind@gmail.com
}

Received: June 23, 2011

Accepted: July 13, 2011

doi:10.5539/cis.v4n5p111

\begin{abstract}
To enhance the identification capacity of the skin-hearing aid for voice signals, the four-channel skin-hearing aid based on Morse encoding method is proposed in this article, which can overcome many disadvantages such as low identification rate and bad anti-jamming capability existing in analog variable pressure skin-hearing aid. By processing voices, seeking the corresponding Morse code of voice signals, establishing the skin response voltage sequence by the Morse encoding, stimulating the skins by this voltage sequence, and making the skins to more clearly feel different signals of voice, the identification rate of skin hearing can be enhanced obviously.
\end{abstract}

Keywords: Morse codes, Voice model, Variable pressure skin-hearing aid

\section{Introduction}

Deaf-mutes' hearing and talking is one big problem in the world, and to solve this problem, people used various method and aid tools such as hearing-aid, electric cochlea, and speech-reading, which are helpful for deaf-mutes' hearing and talking, but there is no one method which can solve this problem perfectly. Though the variable pressure skin-hearing aid prevented by Professor Li Jianwen in Shaanxi University of Science \& Technology (Li, 2004, P. 66-69) could achieve certain effect for the hearing, but it is still not ideal for the voice identification. To improve the voice identification effect in the skin hearing, several key approaches in the variable pressure skin-hearing aid are improved in this article.

Frist, the pronunciation of Chinese language is classified. Second, the voice base based on intelligent voice identification is established by the computer voice identification technology. Third, the exterior voice signals are converted into the digital signals and the corresponding relationship with the voice model base is established. Fourth, the corresponding relationship between the voice model and the Morse code is designed. Fifth, the four-channel Morse encoding method is designed. Sixth, the output signals such as point and line in Morse codes are confirmed. Seventh, the identified voice information output is exported as the analog current signals based on Morse encoding principle. Finally, the voice identification of deaf people's hearing based on the voice model is realized.

\section{Principle of the Four-channel skin-hearing aid}

The multi-channel skin-hearing aid based on Morse codes is mainly composed by the microphone, the filter, the $\mathrm{ADC}$ and $\mathrm{DAC}$, the voice processor, the audio-frequency amplifier, the small-power transformer, and the planar electrode (seen in Figure 1).

Microphone: Acquire voice signals and convert the signals to analog current signals.

Filter: Identify the environmental voices, increase the voice signals, and eliminate the noise signals.

ADC/DAC: The digital signals are better than the analog signals in the identification degree, the anti-jamming capacity, and the establishment of voice model, so the analog signals should be converted to the digital signals for processing. 
Process $\rightarrow$ Voice base $\rightarrow$ Morse codes: Provide the digital signals corresponding with inputs, based on Morse encoding.

Power transformer: Increase the voltage signals to the secure range in which people can feel (Li, 2006, P. 253-257).

Planar electrode: Stimulate the nerve of skin.

\section{Design scheme}

\subsection{Establishment of the voice model of computer voice identification technology}

At present, the voice identification technology has been a comprehensive technology including acoustics, linguistics, digital signal processing, and statistical pattern recognition (Wang, 2009, P. 28-30). The modern v system based on the voice identification technology has been applied in many scenes successfully, and the technologies adopted in different tasks are different. The theoretical research thought of the multi-channel skin-hearing aid based on Morse codes includes classifying the deaf' languages, establishing a set of voice model base according with daily standards, and then providing the voltage sequence based on Morse codes by checking corresponding Morse codes and combining with the response of skin for the planar electrode voltage, and hearing voice by this sequence.

\subsection{Corresponding relationship between voice base and Morse codes}

Morse code is a kind of signal code with break (Li, 2011, P. 5-10), and it expresses different English characters, numbers, and punctuation marks through different sort orders. Generally speaking, any code which can express the written characters by the signals with variable length could be called as Morse code. Aiming at the deaf' voice identification, the new Morse encoding method respectively encodes the initial consonants and the final sounds (seen in Figure 2 and Figure 3). This experiment selects four channels as the output of signals, which corresponds with the searching algorithm, and the programming result shows that the binary tree four-depth algorithm could quickly and exactly find the corresponding signals, and the amount of channel is closely related with the depth.

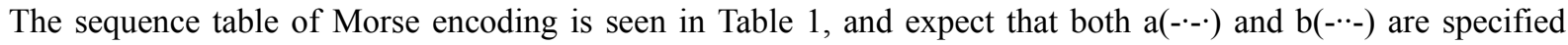
codes, other codes correspond with the binary tree searching algorithm.

\subsection{Implementation method}

The signals with different voltages produced by the analog signal producer are used to stimulate the skin, and when the voltage equals to $100 \mathrm{~V}$, the identification effect is good, and the test report for the deaf-mute is seen in Table 2 .

\section{Tests and conclusions}

The deaf-mute male who is 50 years old is selected as the test object, and the electrode is wear at the front of the left arm, inside of the wrist. $100 \mathrm{~V}$ simulation voltage is selected to achieve good perception effect, and to distinguish the long and the short obviously, large numbers of tests show that the best durative time to feel the short is $0.02 \mathrm{~s}$, and the best durative time to feel the long is $0.05 \mathrm{~s}$. With the help of the skin-hearing aid, the deaf could identify simple voice signals through about 2 hours' training. Through about 50 times of test, for ten numbers from 0 to 9 , except 4 and 7 could not be identified well, which correct recognition rate was only $60 \%$, other numbers could be identified well, with the correct recognition rate above $86 \%$. The voice identification is the process with continual studying and training, and through long-time training, the deaf could obtain good voice identification capability with the help of the skin-hearing aid. The test result shows that the four-channel skin-hearing aid based on Morse code proposed in this article has good voice identification effect.

\section{References}

Li, Jianwen. (2004). Initial Research on the Device of Hearing by Skin with Transformer. Journal of Shaanxi University of Science \& Technology, 22(6), pp. 66-69. doi:cnki:ISSN:1000-5811.0.2004-06-017,

Li, Jianwen, Liu, Ye \& Han, Xuejun. (2006). Response of Skin to Audible Signals. Technical Acoustic, 25(3), pp. 253-257.

Li, Jianwen \& Zhao, Xiaoyu. (2011). Intelligent Skin-hearing Based on Morse Code. Microelectronics \& Computer, 1, pp. 5-10.

Wang, Lihua. (2009). Design and Application of the Pronunciation Signal Producing Model. Informationization, 7, pp. 28-30. 
Table 1. Sequence table of Morse encoding

\begin{tabular}{|c|c|c|c|c|c|}
\hline Character & Code & Character & Code & Character & Code \\
\hline $\mathrm{a}$ & $\cdots$ & en & $\cdots$ & g & ...* \\
\hline o & $* * *$ & in & .... & $\mathrm{k}$ &..$* *$ \\
\hline e & $-* * *$ & un & $\cdot \cdot \cdot \cdot$ & $\mathrm{h}$ & $\cdot--{ }^{*}$ \\
\hline $\mathrm{i}$ &..$* *$ & ün & ..-- & $\mathrm{j}$ & $\ldots *$ \\
\hline $\mathrm{u}$ &.$-* *$ & ang & -.- & $\mathrm{q}$ & $-\cdot-* *$ \\
\hline$\ddot{\mathrm{u}}$ &.$* * *$ & eng & $\cdot-\cdot$ & $\mathrm{x}$ &.$- \cdot *$ \\
\hline ai & $--* *$ & ing & $\cdot---$ & $\mathrm{zh}$ & $---*$ \\
\hline ei & $\ldots *$ & ong & $\ldots$ & $\mathrm{ch}$ & $\ldots$ \\
\hline ui & ...* & $\mathrm{b}$ & $\cdots-$ & sh & $\cdots-$ \\
\hline ao & $\cdot . * *$ & $\mathrm{p}$ & $* * * *$ & $r$ & 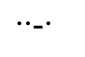 \\
\hline ou & $\cdot--*$ & $\mathrm{~m}$ & $-* * *$ & z & $\cdot \cdot-$ \\
\hline iu & $\ldots * *$ & $\mathrm{f}$ &..$* *$ & $\mathrm{c}$ & $\cdot \cdot \cdot \cdot$ \\
\hline ie & $-\cdot-*$ & d & $\cdot-* *$ & $\mathrm{~s}$ & $\cdot \cdot \cdot$ \\
\hline üe &..$- * *$ & $\mathrm{t}$ &.$* *$ & $\mathrm{y}$ & $\cdot--\cdot$ \\
\hline er & ---* & $\mathrm{n}$ & $--* *$ & $\mathrm{w}$ & $\cdot---$ \\
\hline an & $\ldots$. & 1 & $\ldots *$ & & \\
\hline
\end{tabular}

Note: “-” denotes long, “." denotes short, and “*” denotes mute. 
Table 2. Deaf-mute's simple test (the data from the first group is used for references)

\begin{tabular}{|l|l|l|}
\hline \multicolumn{2}{|c|}{$\begin{array}{r}\text { Tester: male, } 52 \\
\text { years old }\end{array}$} & \multirow{2}{*}{ Identification effect } \\
\hline $\begin{array}{c}\text { Time (s): } \\
\text { short }\end{array}$ & $\begin{array}{c}\text { Time } \\
(\mathrm{s}): \text { long }\end{array}$ & \multicolumn{1}{|l|}{} \\
\hline 0.01 & 0.03 & $\begin{array}{l}\text { The identification effects of long and short are weak, and the difference } \\
\text { between long and short is not obvious. }\end{array}$ \\
\hline 0.01 & 0.04 & $\begin{array}{l}\text { The identification effect of short is weak, and the identification effect of long } \\
\text { increases gradually. }\end{array}$ \\
\hline 0.01 & 0.05 & $\begin{array}{l}\text { The identification effect of short is weak, and the identification effect of long } \\
\text { increases gradually. }\end{array}$ \\
\hline 0.02 & 0.03 & $\begin{array}{l}\text { The identification effect of long is weak, and the identification effect of short } \\
\text { increases gradually, and the long and the short are difficult to be identified. }\end{array}$ \\
\hline 0.02 & 0.04 & $\begin{array}{l}\text { The identification effects of short and long increase, but the long and the } \\
\text { short are difficult to be identified. }\end{array}$ \\
\hline 0.02 & 0.05 & $\begin{array}{l}\text { The identification effects of short and long increase obviously, and the long } \\
\text { and the short are easy to be identified. }\end{array}$ \\
\hline 0.03 & 0.04 & $\begin{array}{l}\text { The identification effect of short increases obviously, and the identification } \\
\text { effect of long increases gradually, but the long and the short are difficult to } \\
\text { be identified. }\end{array}$ \\
\hline 0.03 & 0.05 & $\begin{array}{l}\text { The identification effects of short and long increase obviously, but the long } \\
\text { and the short are difficult to be identified. }\end{array}$ \\
\hline 0.03 & 0.06 & $\begin{array}{l}\text { The identification effects of short and long increase obviously, and the long } \\
\text { and the short are easy to be identified, but the time consumes long. }\end{array}$ \\
\hline 0.04 & 0.05 & $\begin{array}{l}\text { The identification effects of short and long increase obviously, but the long } \\
\text { and the short are difficult to be identified. }\end{array}$ \\
\hline 0.04 & 0.06 & $\begin{array}{l}\text { The identification effects of short and long increase obviously, and the long } \\
\text { and the short are easy to be identified, but the time consumes long. }\end{array}$ \\
\hline
\end{tabular}

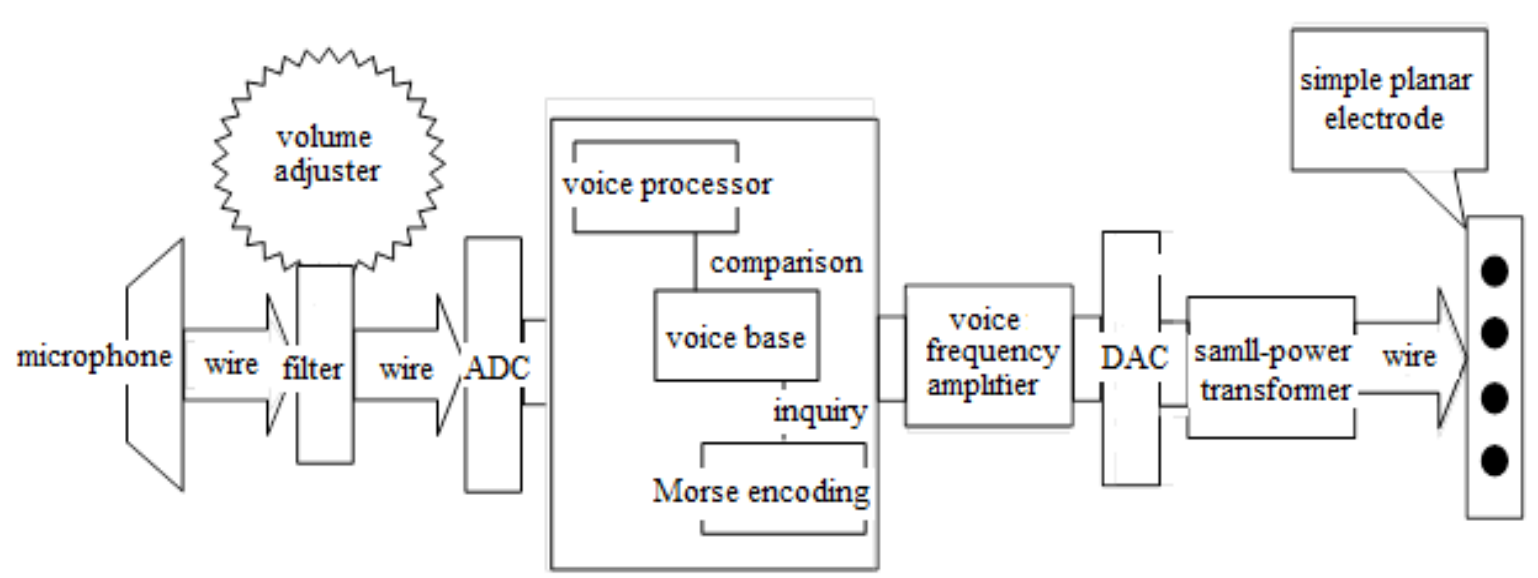

Figure 1. Four-channel Skin-hearing Aid Principle Based on Morse Encoding 


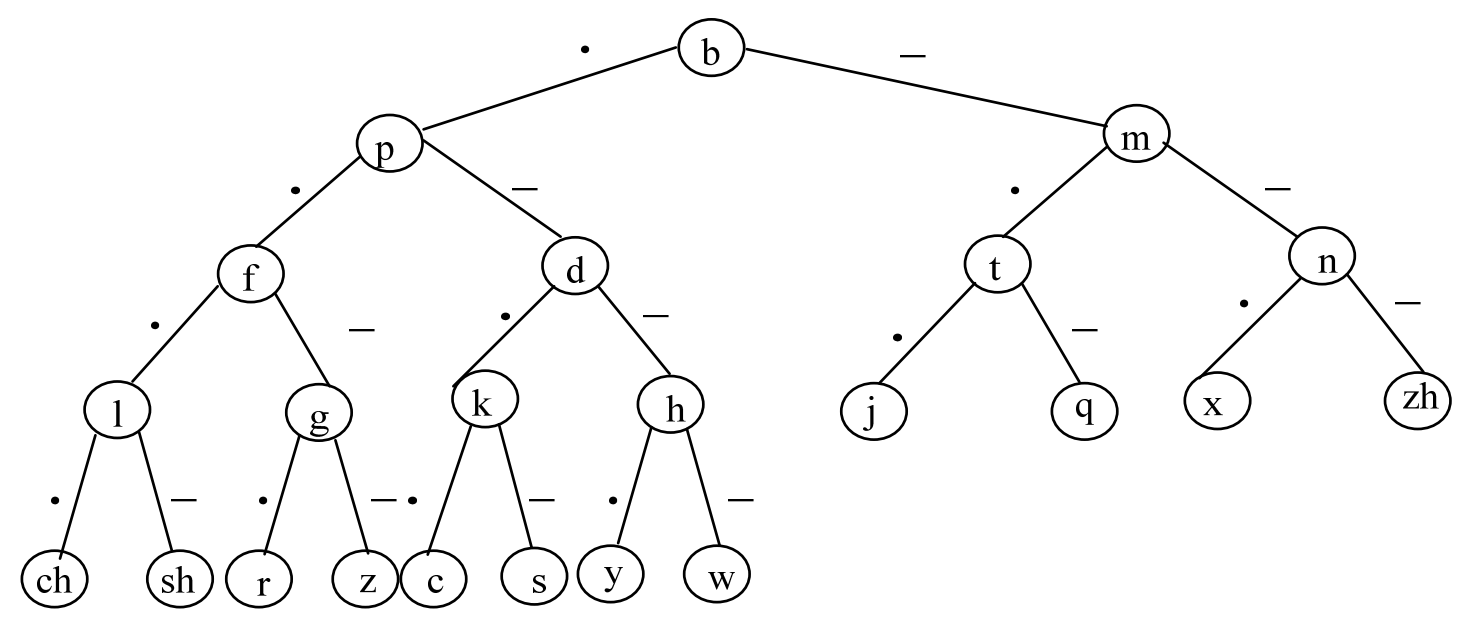

Figure 2. Morse Initial Consonant Encoding Table

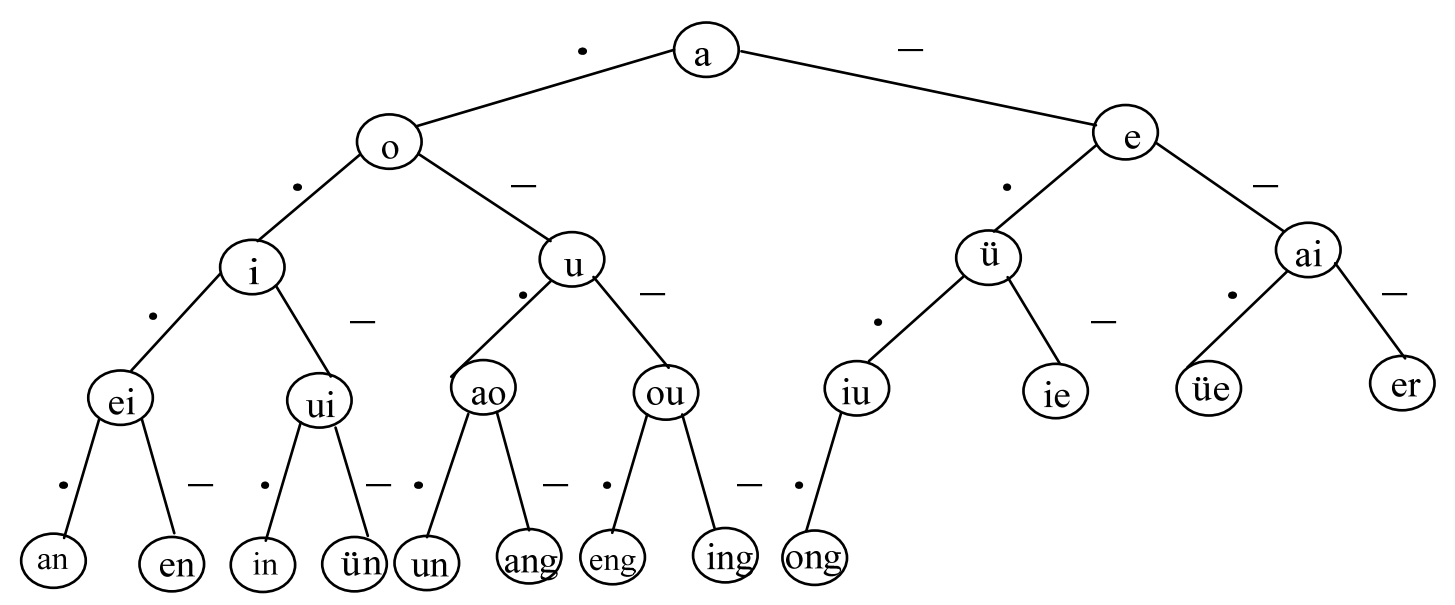

Figure 3. Morse Final Sound Encoding Table 